\title{
Atividades lúdicas inclusivas junto a alunos com deficiência intelectual nas aulas de Ciências ${ }^{1} .$.
}

\author{
Andréa Nóbrega Juliano² \\ Débora Pereira Laurino ${ }^{3}$ \\ Simone Silveira Silva ${ }^{4}$
}

\begin{abstract}
Resumo:
A deficiência intelectual é desafio que merece olhares atentos e cuidadosos, os quais provocam o ressignificar de nossas ações educativas, principalmente, no que se refere ao planejamento das aulas de Ciências. Nessa perspectiva, apresentamos uma pesquisa que tem sua origem na sala de aula; decidimos, assim, pelo Método Cartográfico, pela Biologia do Conhecer e Biologia do Amar, por estarmos imersas, como professoras-pesquisadoras, em espaço fluido, em processo de reflexão sobre nossa práxis. Cartografamos o que nos atravessa, a acompanhar um processo, e não a representar um objeto. Dessa maneira, trazemos atividades lúdicas que (re) inventamos, na Escola de Educação Básica Dr. Getúlio Vargas, em Cachoeira do Sul, com alunos com deficiência intelectual, a partir das experiências de uma das autoras, em estágio, no Curso de Licenciatura em Ciências. Desenvolvemos um estudo reflexivo-prático pela necessidade de nos responsabilizarmos pelo ensinar e pelo aprender no amor que legitima. Compreendemos que é possível trazer o lúdico em interação com atividades que consideramos ser tão singelas quanto pertinentes e repletas de sentires, ao processo de inclusão, por possibilitarem condições para construção de saberes aos alunos a partir de suas características intelectuais e pelos movimentos em Ciências.
\end{abstract}

\section{Palavras-chave:}

Inclusão. Deficiência intelectual. Atividades lúdicas. Ciências.

\footnotetext{
1 Apoio CAPES: Enfatizamos que fazemos uso das reticências, com sentido de processo, como recurso linguístico-discursivo; grafamos (trans)formar, (des)construção, por considerarmos formação de professores em processos inventivos para além de. 2 Doutora em Educação em Ciências pela Universidade Federal do Rio Grande - FURG - e Mestre em Linguística Aplicada ao Ensino de Línguas pela Universidade Católica de Pelotas - UCPEL. E-mail: andreanjuliano@gmail.com. ORCID iD: http://orcid. org/0000-0002-2442-5615.

3 Doutora em Informática na Educação e Mestre em Ciências da Computação pela Universidade Federal do Rio Grande do Sul - UFRGS. E-mail: deboraplaurino@gmail.com. ORCID iD: http://orcid.org/0000-0002-3360-0374.

4 Licenciada em Ciências pela Universidade Federal do Rio Grande - FURG. E-mail: simone_silveira03@hotmail.com. ORCID iD: http://orcid.org/0000-0002-3777-3571.
} 


\title{
Practices in recreational inclusion activities with disabled people intellectuals in science classes...
}

\begin{abstract}
:
Intellectual disability is a challenge that deserves attentive and careful eyes, which cause the resignify of our educational actions, especially with regard to the planning of science classes. From this perspective, we present a research that has its origin in the classroom; thus, we decided by the Cartographic method, by the Biology of Knowing and Biology of Amar because we are immersed, as teaching-researchers, in a fluid space, in a process of reflection on our praxis. We cartograph what goes through us, accompanying a process, not representing an object. Thus, we bring playful activities that (re) we invented, at the School of Basic Education Dr. Getúlio Vargas, in Cachoeira do Sul, with students with intellectual disabilities, from the experiences of one of the authors, in internship, in the Undergraduate Course in Sciences. We developed a reflexive-practical study by the need to take responsibility for teaching and learning in the love it legitimizes. We understand that it is possible to bring the playful in interaction with activities that we consider to be as simple as relevant and full of feelings, to the inclusion process, because they enable conditions for the construction of knowledge to students from their intellectual characteristics and movements in Science.
\end{abstract}

Keywords:

Inclusion. Intellectual disability. Recreational activities. Sciences.

\section{Prácticas en actividades de inclusión recreativa con personas disca- pacitadas intelectuales en clases de ciencias...}

\section{Resumen:}

La discapacidad intelectual es un reto que merece miradas atentas y atentas, que provocan la resignificación de nuestras acciones educativas, especialmente en lo que se refiere a la planificación de las clases de ciencias. Desde esta perspectiva, presentamos una investigación que tiene su origen en el aula; así, nos decidimos por el método Cartográfico, por la Biología del Conocimiento y Biología de Amar porque estamos inmersos, como docentes-investigadores, en un espacio fluido, en un proceso de reflexión sobre nuestra práxis. Cartografiamos lo que pasa por nosotros, acompañando un proceso, no representando un objeto. Así, traemos actividades lúdicas que (re) inventamos, en la Escuela de Educación Básica Dr. Getúlio Vargas, en Cachoeira do Sul, con estudiantes con discapacidad intelectual, a partir de las experiencias de uno de los autores, en prácticas, en el Curso de Pregrado en Ciencias. Desarrollamos un estudio reflexivo-práctico por la necesidad de asumir la responsabilidad de enseñar y aprender en el amor que legitima. Entendemos que es posible llevar lo lúdico en interacción con actividades que consideramos tan simples como relevantes y llenas de sentimientos, al proceso de inclusión, porque permiten condiciones para la construcción del conocimiento a los estudiantes desde sus características intelectuales y movimientos en la Ciencia.

Palabras clave:

Inclusión. Discapacidad intelectual. Actividades recreativas. Ciencias.

\section{Contextualizando...}

No presente artigo, cartografamos nossa experiência em relação à inclusão de alunos com diagnóstico de deficiência intelectual. Para isso, inicialmente, realizamos no coletivo uma breve reflexão sobre esse tema e, posteriormente, apresentamos algumas atividades que foram construídas, 
com alunos, no estágio vivenciado, em 2017, por uma das autoras deste artigo, em aulas de Ciências, no ensino fundamental, em classes nas quais a autora atuou como monitora e, hoje em dia, como professora de Ciências.

Conforme sabemos, a inclusão é um processo que nos desafia, pois criar atividades adaptadas para alunos com deficiência intelectual é recorrente, na maioria das escolas brasileiras. A inclusão de alunos com deficiência intelectual nas aulas de Ciências foi o tema escolhido por uma das autoras, com base em suas vivências que transbordam sentidos, com possibilidades de, na disciplina de estágio em Ciências, no Curso de Licenciatura em Ciências, da Universidade Federal do Rio Grande - FURG. Em momento inicial, na sala de aula, a autora observou que os alunos com deficiência intelectual não se sentiam incluídos nas aulas, já que não participavam das atividades e permaneciam parados, inertes, por todo o período do encontro. Em algumas vezes, um dos alunos se mostrava agitado e, então, por assim estar, em total desconforto no transcorrer dos encontros. $\mathrm{E}$, nessas condições, iniciamos a problematizar o que nos movimenta a pesquisar: Como convidar alunos com deficiência intelectual a serem sujeitos autopoiético-discursivos protagonistas da construção dos seus saberes? Como despertar condições de possibilidades de interação? Desejamos, pois, despertar não respostas, mas práticas lúdicas que contribuam para o desenvolvimento de nossos alunos à margem de processos educacionais pedagógicos muitas vezes excludentes. Legitimarmos o outro sugere estarmos em interações recursivas que provocam transformações nos sujeitos e no meio, as quais são, conforme Maturana (2014a), congruentes, uma vez que resultam das interações recorrentes de coordenações consensuais de condutas, porque dependem da história de interações recorrentes, e porque surgirão da contingência das mudanças estruturais de ambos.

Desenvolvemos a pesquisa cartográfica com a qual visamos ao acompanhamento de processos, pois a cartografia requer que a escuta e o olhar se ampliem, sigam para além do puro conteúdo da experiência vivida, do vivido da experiência ao incluir seu espaço genético, sua dimensão processual, da experiência apreendida em seus movimentos. Como cartógrafas, nada em si e a nós se fecha, pelas condições de possibilidades de escolhas que têm lugar face às características de cada experiência. Vivenciamos o método como hódus-metá “[...] como uma aposta na experimentação do pensamento - um método não para ser aplicado, mas para ser experimentado e assumido como atitude [...]" (PASSOS; ESCÓSSIA; KASTRUP, 2014, p. 10-11). Ao mesmo tempo, lembremo-nos dos procedimentos metodológicos presentes em nossas práticas (TEDESCO, 2008). Interessante sublinharmos o caráter facultativo e provisório em relação aos métodos e às estratégias. No caso do método dos procedimentos, trata-se bem mais do compartilhamento de certa direção, de sugestões sobre modos de agir dirigido à instalação de graus de abertura à indeterminação, que funciona como um conjunto aberto de pistas que servem para sugerir encaminhamentos, mas também para serem equivocadas (DELEUZE; GUATTARI, 2017). Diante disso,

[...] por processo entendemos aqui a dimensão da processualidade da cognição, e não de processamento de informação. [...] é o processo de conhecimento em sua dimensão temporal, que responde por sua transformação permanente. Por um lado, os processos de criação de si, os devires cognitivos e a dimensão pragmática da cognição; por outro, temos o si mesmo cognitivo, os regimes cognitivos e os regimes de signos (KASTRUP; TEDESCO; PASSOS, 2008, p. 11).

Sendo assim, consideramos a (des)construção de saberes, no ensinar e no aprender, com e nas experiências em práxis reflexivas sobre como se faz o que se faz. Nessa perspectiva científica, fazemos ciência, como observadores, ao explicar o que observamos. Como observadores, somos seres humanos e nos encontramos na linguagem fazendo distinções quando começamos a refletir sobre o que fazemos, e como fazemos o que fazemos, ao operarmos como animais linguajantes (MATURANA, 2014a). Nossa pesquisa tem sua origem na sala de aula; decidimos, assim, pelo método Cartográfico, pela Biologia do Conhecer e pela Biologia do Amar, por estarmos imersas 
como professoras-pesquisadoras nesse espaço fluido e, nessas condições, no constante processo de reflexão sobre a nossa práxis. Somos sujeitos autopoiético-discursivos, pois consideramos que somos linguagem em histórias e vivências. Daí, nosso potencial de nos autorreproduzirmos pelas condições do experienciar. Dessa forma, criamos condições para um trabalho coletivo e reflexivo pelo viés da linguagem. Consideramos que a Biologia do Conhecer e a Biologia do Amar que estudamos no Grupo de Pesquisa Educação Científica: as Tecnologias Educativas no Processo de Aprendizagem, na Universidade Federal do Rio Grande, possibilitam-nos, como cartógrafas, legitimar o conversar que nutre nosso encontro com o outro. E, para pesquisar, compreendemos o linguajar e o conversar pela nossa coexistência sensorial, operacional e relacional, as quais geram cada um dos mundos em que habitamos (MATURANA; YÁÑES, 2015). Ensinar é fascinante e, ao mesmo tempo, uma prática que exige amor, comprometimento e dedicação; o ensinar é, sempre, diferente e flexível. Consideramos que o amor não é um sentimento, é um domínio de ações nas quais o outro é constituído como um legítimo outro na convivência (MATURANA, 2009). Interação, na perspectiva em que vivenciamos, significa constituir a si e ao outro, sugere que tocamos e que somos tocados e, nesses movimentos, a interação é o caminho e o próprio caminhar, os quais criam um cenário no qual as perturbações ocorrem e provocam alterações significativas em cada um dos seres vivos que estiver implicado no processo (MATURANA, 2014a). Conversar nos convoca aos entrelaces do racional e do emocional. Na posição de observadoras implicadas, não falamos sobre, mas falamos com e no processo; portanto, com o conversar, assumimos a posição de quem explica na imersão da objetividade, entre parênteses, porque, conforme Maturana e Yáñes, (2015),

[...] sabemos y entendemos, desde las coherencias de nuestro vivir sensorial-operacional-relacional, que en el acto de distinguir lo que distinguimos operando como seres humanos en el lenguajear, el conversar y el reflexionar, conscientes de hacerlo que hacemos, operamos como observadores.[...] en cada recursión en nuestro conversar surge un dominio intrínsecamente nuevo de distinciones y de coordinaciones de haceres, sentires y emociones que constituye la posibilidad de un vivir y convivir un mundo que es, de hecho, completamente nuevo (MATURANA; YÁÑES, 2015, p. 325).

Pesquisamos de maneira inventiva e aberta ao fluxo da linguagem em um conversar em sentires que se transformam e nos transformam em condições sócio-histórico-ideológico-culturais nas quais estamos em modus vivendi. Observamos com, no e pelo caminho explicativo da objetividade entre parênteses o processo de interação que se constitui em nós, professores e alunos, por nossa capacidade de transformar a nós e ao outro.

Destacamos que a linguagem em ação, o linguajar ${ }^{5}$, nos possibilita estarmos no refletir (MATURANA, 2014a). Elencamos algumas ideias pertinentes às nossas compreensões acerca da linguagem: somos humanos, somos seres linguajantes por natureza; somos individuais e, paradoxalmente, coletivos; somos sócio-históricos, somos, pois, a linguagem que construímos no nosso experienciar. "Nós, seres humanos, acontecemos na linguagem, e acontecemos na linguagem enquanto o tipo de sistemas vivos que somos. Não temos nenhuma maneira de nos referirmos a nós mesmos, ou a qualquer outra coisa, fora dela" (MATURANA, 2014b, p. 319). Somos sujeitos autopoiético-discursivos pela nossa capacidade de transformação em si na e pela linguagem em discursos; somos seres reflexivos com historicidade. Portanto, somos biológicos e discursivos na e pela linguagem que nos constitui em um conversar. A reflexão é um processo de conhecer como conhecemos, é um ato de voltar a nós mesmos, a única oportunidade que temos de descobrir nossas cegueiras e reconhecer que as certezas e os conhecimentos dos outros são, respectivamente, tão aflitivos e tão tênues quanto os nossos (MATURANA; VARELA, 2011). E, somente refletimos

5 Maturana emprega 'linguajar', e não 'linguagem', ao enfatizar seu caráter de atividade, de comportamento e evita a associação com uma 'faculdade' própria da espécie. 
a partir de nossas experiências em conversar, em sentires pelos quais tocamos e somos tocados. Jogamo-nos nas possibilidades do estar com o outro e resvalamos sentidos.

\section{Territórios pelos quais trilhamos...}

Cartografamos experiências no ensinar e no aprender Ciências na contemporaneidade pelo conviver, na sala de aula, que nos possibilita condições para tal. Somos professoras e, com nossos alunos em formação, operamos uma mudança da epistemologia da prática para a epistemologia da práxis, porque práxis são movimentos operacionalizados, simultaneamente, pela ação e pela reflexão. Não separamos teoria, prática, vida e transformação. Na busca com e pelo caminho explicativo, entre parênteses, em que estamos implicadas, pesquisamos imersas na experiência a ser validada e explicada (MATURANA, 2014a). Participamos, então, da experiência através de nossas ações de explicar. Implicadas, reconhecemos que, em nosso ato de observar, modificamos tanto a nós quanto ao que observamos.

Vivenciamos práticas que permeiam o ensinar e o aprender, nas aulas de Ciências, na constituição do sujeito autopoiético-discursivo que somos no processo de interação no e pelo linguajar em sentires. Aceitamos o outro como legítimo outro e experienciamos o emocionar da aceitação, o que nos torna mais sensíveis a si e ao outro na condição de sujeitos heterogêneos que somos. Convivemos em igualdades nas diferenças, ou seja, legitimamos que cada um contribui com seus saberes em (des)construção com diferentes vivências e histórias. Compreendemos a sala de aula como férteis territórios nos quais engendramos emoção e razão que nos transformam. Isso então nos movimentou a vivenciar algumas atividades lúdicas, realizadas na Escola Municipal Dr. Getúlio Vargas, em Cachoeira do Sul, RS, com estudantes com deficiência intelectual, a partir das experiências de uma das autoras em seu estágio, no Curso de Licenciatura em Ciências, e a monitoria que envolve o apoio aos alunos com deficiência intelectual. Alguns conteúdos relacionados à disciplina de Ciências incluem vários nomes difíceis de memorizar e, muitas vezes, termos mais complexos tornam as aulas um tanto fatigantes, o que desmotiva os alunos ao processo de aprender. Assim, consideramos que as atividades lúdicas podem minimizar esse desconforto e não só os alunos com deficiência são beneficiados, mas todos os estudantes da classe, o que pode auxiliar no aprendizado e possibilitar a interação entre alunos e professores nas aulas de Ciências. O ensino de Ciências, em sua maioria, segue o modelo tradicional de ensino que valoriza a reprodução e não leva o aluno a pensar do seu jeito e no seu tempo. Isso desmotiva o aluno e, como consequência, desencadeia desinteresse e passividade.

Então, consideramos que as aulas tradicionais, em sua maioria, são ainda descompassadas em relação à realidade dos alunos, o que pode gerar, por entre outras questões, incompreensões do que estamos a construir, pois os alunos não conseguem dar sentido ao que é e está desconexo às vivências (KRASILCHIK, 2008). Diante disso, relevamos vivências-experiências, em relação ao que discutimos, no Grupo de Pesquisa, Educação Científica: as Tecnologias Educativas no Processo de Aprendizagem, na Universidade Federal do Rio Grande, que passam a ressignificar, porque vivenciamos, em diferentes níveis e áreas, o aprender e o ensinar em que observamos o distanciamento entre o que temos como proposta, como escola, e o que, de fato, faz sentido e se torna fazer em práxis. E no desejo de que nossas ações docentes despertem sentidos, ratificamos nossas experiências em aprendizagens com alunos com deficiência intelectual, uma vez que, na interação com eles, percebemos as formas específicas pelas quais compreendem conceitos abstratos. Assim, consideramos necessária a utilização de estratégias como a utilização de material concreto, como jogos e brincadeiras que auxiliem os alunos, sobretudo os com deficiência intelectual, a desenvolverem compreensões e saberes em processos cognitivos. 
Com o nosso estudo, não procuramos o inédito, porém desejamos apresentar algumas das atividades lúdicas possíveis para que, se confeccionadas e apreciadas com os alunos com deficiência intelectual, possamos construir no coletivo não só conceitos, mas, também, possibilitar a interação e a cooperação, para que a construção de saberes faça sentido e que possa, assim, criar condições de possibilidades para o desenvolvimento sócio, cognitivo, cultural e ético dos nossos alunos. Nesse sentido, a seguir trazemos algumas compreensões sobre inclusão. Para isso, descrevemos algumas das atividades as quais planejamos, que vivenciamos com alunos com deficiência intelectual e, após, tecemos algumas considerações sobre a inclusão de estudantes com deficiência intelectual no ensino regular. Como embasamento teórico para o presente trabalho, no qual temos como desejo nossos olhares e possibilidades com e sobre deficiência intelectual, trazemos para a conversa Maria Teresa Eglér Mantoan, professora doutora em Educação, que pesquisa na área de inclusão escolar, além de Adriana Lima Verde, dentre outros. Seguimos a tecer o fio discursivo em: Por deficiência intelectual; Educação e inclusão; Como nos movimentamos e atividades lúdicas.

\section{Por deficiência intelectual...}

Destacamos que deficiência é o termo que usamos para definir que uma pessoa tem ausência ou disfunção em uma das estruturas físicas ou psíquicas (MENDONÇA, 2010). Não compreendemos deficiência no sentido de incapacidade, pois, como sujeitos autopoiético-discursivos, somos capacidades em vivências. Crianças que têm desenvolvimento cognitivo diferenciado devido a lesões ocorridas no cérebro, que afetam seus processos cognitivos, são consideradas crianças com deficiência.

A condição de pessoa com deficiência intelectual não pode nunca predeterminar qual será a capacidade de aprendizagem do aluno, precisamos atender, então, as suas especificidades sem desviar dos princípios básicos da educação proposta aos demais estudantes. Ou seja, como professores, é importante buscarmos diversas formas de auxiliar a compreensão do estudante, sem minimizar ou evitar o desenvolvimento de algum conteúdo que esteja sendo trabalhado com os demais alunos da classe (OLIVEIRA, 2008). Trabalhar com alunos com deficiência intelectual é um grande desafio, pois exige muita dedicação e atualização por parte dos educadores. Precisamos conhecer nosso aluno, entender as dificuldades e as limitações que a deficiência lhe causa, sobretudo para superar os desafios. Ouvir nossos alunos a partir de diferentes compreensões e interações possibilita trocas e afetos de estarmos com e para o outro.

\section{Educação e inclusão...}

$\mathrm{Na}$ busca de entendermos sobre a inclusão, não podemos deixar de referenciar a Declaração de Salamanca, documento firmado pela Organização das Nações Unidas (ONU, 1994), que se tornou o principal norteador da inclusão escolar. Esse documento foi constituído em assembleia na Conferência Mundial de Educação Especial, entre sete e dez de junho de 1994, em que os países participantes, dentre eles, o Brasil, se comprometeram em garantir uma educação para todos viabilizando, com urgência, políticas de inclusão para crianças, para jovens e para adultos com necessidades educacionais especiais, dentro do sistema regular de ensino. Sabemos que educação é um direito de todos, incluindo alunos com deficiências, e que compete, 
assim, aos governantes darem suporte necessário para que isso aconteça. De acordo com a Lei ${ }^{6}$ $n^{\circ}$ 13.146, de 2015 - Lei brasileira de inclusão da pessoa com deficiência (LBI): o capítulo IV aborda o direito à educação, com base na Convenção sobre os direitos das pessoas com deficiência, que deve ser inclusiva e de qualidade em todos os níveis de ensino; garantir condições de acesso, permanência, participação e aprendizagem, por meio da oferta de serviços e recursos de acessibilidade, os quais eliminem as barreiras. O Atendimento Educacional Especializado (AEE) também está contemplado, entre outras medidas. Como professoras, compreendemos que essa lei, na maioria das situações, não se faz valer em um país de desigualdades, mas nos provoca a redimensionar nossas práticas em sala de aula.

Dessa forma, não podemos deixar de observar que vivemos, infelizmente, em um Brasil que tem como marca políticas públicas que não são assumidas, em grande parte, pelo próprio governo que as legitima apenas no plano teórico. A educação escolar é essencial para o desenvolvimento da criança, do jovem, pois compreende a base para a formação do sujeito como um todo. É realidade que através de uma educação comprometida teremos oportunidades pessoais e profissionais diferenciadas ao longo da vida, na condição de exercício pleno de ser cidadão. $O$ momento é de transformar a escola em um espaço único, para pessoas com deficiência ou não (MANTOAN, 2006). Assim,

[...] as condições de que dispomos, hoje, para transformar a escola nos autorizam a propor uma escola única e para todos, em que a cooperação substituirá a competição, pois o que se pretende é que as diferenças se articulem e se componham e que os talentos de cada um sobressaiam (MANTOAN, 2006, p. 198).

Consideramos que a cooperação, a troca e a interação entre as diferenças seja um dos caminhos possíveis para escola e sociedade, que consideram o diferente em processos inclusivos de legitimação. A lógica e a emoção da cooperação são adversas à competição; a cooperação é a aceitação do outro como legítimo na convivência (MATURANA, 2009), é o respeito à diversidade. Compreendemos por interação no ensinar e no aprender que estamos com o outro, para o outro e vice-versa. A interação não é resultado de algo, mas o processo mesmo - causa e consequência - ao mesmo tempo, da novidade e da mudança. Então, o ensino e o afeto estão, intrinsecamente, associados (MATURANA, 2014a). Compreendemos, com os movimentos desse pesquisador, que, como seres humanos, somos o que somos no conversar, mas na reflexão podemos mudar nosso conversar e nosso ser. Essa é nossa liberdade, a qual pertence ao nosso ser psíquico e espiritual. O estar 'com o outro' e 'para o outro' se efetiva no transcorrer das nossas conversas. Como sabemos, a educação inclusiva é um tema discutido em seminários e em formação continuada de professores, visto que, a cada ano que passa, mais alunos com deficiência intelectual chegam às escolas de ensino regular. Porém, a formação inicial e continuada dos professores ainda contempla um planejamento que considera a compreensão dos estudantes como semelhantes em compreensões e comportamento (MRECH, 2001). Parece-nos que não está em nossa ação e entendimento lidar com a inclusão, com a diferença de ser do estudante, o que inclui considerar suas emoções, suas expectativas, suas reações e compreensões. Ainda não está no âmago da profissão docente, na atualidade, lidar com a diferença que inclui algumas patologias; requer, para isso, formação e estudo. Destacamos a necessidade de mudança nas atitudes e comportamentos que excluem os alunos com deficiência nas escolas. Compreendemos que é fácil receber os alunos que aprendem,

6 Para ler, acessar: http://www.google.com/url?q=http\%3A\%2F\%2Flegislacao.planalto.gov.br\%2Flegisla\%2Flegislacao.nsf\%2FViw_Identificacao\%2Flei\%252013.146-2015\%3FOpenDocument\&sa=D\&sntz=1\&usg=AFQjCNEh1OTrsCIIInqM74mRD5iZjY55LA. Acesso em: 28 out. 2017 
apesar da escola, e é mais fácil ainda encaminhar, para as classes e escolas especiais, os que têm dificuldades de aprendizagem e, sendo ou não alunos com deficiência, para os programas de reforço e aceleração (MANTOAN, 2003). Assim, é urgente assumirmos responsabilidades e compromissos diante da complexidade do ensinar e do aprender. Percebemos que a maioria dos professores não têm formação ou apoio para lidar com a diferença intelectual dos estudantes e, por isso, transfere a responsabilidade de adaptação e de planejamento de atividades específicas para os profissionais especializados. Diante dessa realidade, nos perguntamos o que podemos fazer para alterar essa situação? Por que tenho que pensar na particularidade de cada sujeito? Por que os profissionais envolvidos com esses alunos se julgam incapazes para tal trabalho? Que espaço de discussão, de conversa sobre as aflições dos professores em relação à inclusão está sendo acolhido na escola?

Frente a tantos questionamentos sobre como trabalhar a inclusão dentro da sala de aula, acreditamos que a primeira ação que devemos ter na posição de professor é acreditar no potencial de nossos alunos. Sabemos que o trabalho não é fácil, que os desafios encontrados são muitos, mas o retorno é gratificante e satisfatório para o professor, aluno e familiares. Acreditamos que o professor que aprende junto com seus alunos consegue melhores resultados (MANTOAN, 2008). Certamente, um professor que engendra e participa da caminhada do saber "com" seus alunos consegue entender melhor as dificuldades e as possibilidades de cada um e provocar a construção do conhecimento com maior adequação.

Em uma formação de monitores e professores da educação inclusiva, na rede municipal de educação - APAE em Cachoeira do Sul, RS, realizada em 22 de setembro de 2017, tivemos a oportunidade de ouvir o relato de profissionais envolvidos no processo de inclusão, suas aflições, expectativas e experiências. Nesse momento, debatemos, discutimos, refletimos sobre essas questões e reforçamos a importância das ações do professor para a transformação, para a evolução das escolas no contexto em que vivemos. Com isso, chegamos à conclusão de que é preciso recriar nossa maneira de 'dar aula', saber que cada aluno é diferente, não só os diagnosticados com deficiência, mas todos apresentam particularidades. É preciso olhar o nosso aluno como sujeito único e, assim, ser flexível na nossa maneira de ensinar. Planejar é o primeiro passo para uma aula proveitosa, mas saber mudar esse planejamento ao longo do período é muito importante para dinamizar e para flexibilizar o processo do ensinar e do aprender que efetivamos pela experiência. Assim, é fundamental construir o planejamento de aula a partir do reconhecimento das diferenças de nossos alunos, para que possamos contemplar as especificidades dos estudantes com ou sem deficiência intelectual. Parece-nos interessante utilizarmos diferentes formas de adaptação, a fim de facilitarmos a realização das atividades no processo do ensinar e do aprender. Um bom planejamento precisa levar em conta a realidade escolar, como são os professores e os alunos da escola, levando em conta os problemas sociais e as necessidades da comunidade escolar, isso inclui, as diversidades existentes dentro da sala de aula (COSTA, 2010).

A questão da diversidade vai além das questões culturais e de vivência, já que envolve os diferentes graus de conhecimento entre alunos sobre determinados conteúdos. Daí, a flexibilidade do planejamento escolar ser relevante. Precisamos, então, compreender o processo de aprender dos alunos com deficiência intelectual, valorizar o que ele aprende e apreende pela interação no momento, e estarmos atentos à sua capacidade de criar e de ressignificar a partir da sua história de vida. Precisamos recriar o modelo educativo, e isso requer um trabalho pedagógico diferente do tradicional (MANTOAN, 2003). Assim,

[...] Superar o sistema tradicional de ensinar é um propósito que temos de efetivar com toda a urgência. Essa superação refere-se ao "que" ensinamos aos nossos alunos e ao "como" ensinamos, para que eles cresçam e se desenvolvam, sendo seres éticos, justos, pessoas que terão de reverter uma situação que não conseguimos resolver inteiramente: mudar o mundo e 
torná-lo mais humano. Recriar esse modelo tem a ver com o que entendemos como qualidade de ensino (MANTOAN, 2003, p. 34).

Destacamos que, após tantos anos da afirmativa da referida autora, ainda permanecemos a observar que a realidade da maioria das escolas no Brasil pouco ou nada evoluiu; sabemos, pois, que nem todas as realidades vivenciam o que a legislação determina.

Daí, nossa proposta de práticas com atividades lúdicas ser algo possível, mesmo diante de precariedades, de ausências. Assim, consideramos que existem necessidades que influenciam diretamente no processo do aprender e exigem uma forma de ensinar diferenciada, com a utilização de recursos e com o apoio especializado para esses alunos. Sendo assim, nós, na condição de professores, primeiramente, somos convidados a conhecer nosso aluno e saber quais suas possibilidades, seus desejos, suas dificuldades, para desenvolver ações direcionadas que o auxiliem em suas aprendizagens. Para tanto, ratificamos que o trabalho em conjunto se torna essencial com a professora responsável pelo AEE que, dentro do ambiente escolar, é o profissional habilitado para dar suporte ao professor nesse momento de reformulação dos saberes (VERDE, 2010).

[...] A função do professor de AEE consiste em propor atividades que permitam eliminar barreiras na aprendizagem e otimizar a aprendizagem dos alunos e sua inclusão no ensino regular. Essa ação, certamente, terá uma repercussão positiva no desempenho do aluno na sala de aula comum (VERDE, 2010, p. 34).

O trabalho cooperativo e planejado entre os profissionais da escola poderá melhor auxiliar os alunos. Por isso, o planejamento adaptado para a inclusão, com estratégias diferentes e ações pensadas para o desenvolvimento intelectual do aluno, ao usar como estratégias palavras-chave, colagens e recortes podem levar o aluno a fazer relação do real com o abstrato e contribuírem para o processo do ensinar e do aprender que se faz ao tempo e a compreensão de cada um. Então, a confecção de jogos pedagógicos e o uso de materiais lúdicos são alternativas práticas para a construção de saberes em sala de aula que, além de promover o processo do ensinar e do aprender, proporcionam o movimento da interação entre todos os colegas. A atividade lúdica é uma ferramenta fundamental para o desenvolvimento do aluno com deficiência intelectual, pois através das atividades lúdicas eles têm a possibilidade de desenvolver a coordenação motora, a sua atenção e ainda a interação com os colegas de classe (SANTOS, 2001). O lúdico como um recurso que promove inúmeros benefícios. Portanto,

[...] a ludicidade como ciência se fundamenta sobre os pilares de quatro eixos de diferentes naturezas, isto é, sociológica, psicológica, pedagógica, epistemológica. Sociológica, porque engloba demanda social e cultural. Psicológica, porque se relaciona com os processos de desenvolvimento e de aprendizagem do ser humano em qualquer idade em que se encontre. Pedagógica, porque se serve tanto da função teórica existente, como das experiências educativas provenientes da prática docente. Epistemológica, porque tem fonte de conhecimento científico que sustenta o jogo como fatos de desenvolvimento (SANTOS, 2001, p. 42).

Diante disso, o lúdico tem papel ímpar no processo do ensinar e do aprender para todos os alunos da classe. Porém, é preciso que os profissionais envolvidos estejam preparados com formação adequada, que conheçam os jogos e as atividades que desenvolverão, para que possam mediar, suscitar questionamentos e contornar possíveis imprevistos. Enfatizamos, novamente, que, para os alunos com deficiência intelectual, as atividades lúdicas são ainda mais significativas 
(MAFRA, 2009), porque estimulam, no espaço escolar, a criatividade, a participação e a construção do conhecimento com, na e pela interação.

Destacamos a dissertação de Augusto Marques Alves, da Universidade Federal de São Carlos, ao afirmar que

[...] na última década (2008-2018), a exemplo, temos uma série de Leis, Decretos e Resoluções que se propuseram balizar, sobre o princípio do Estado Democrático de Direito, Políticas e garantias que assegurem um Projeto de Educação de maior qualidade e menos estratificada para todos os estudantes, em especial, o público-alvo da Educação Especial. [...] Cabem críticas a esses dispositivos, no que concerne a fragilidade e alcance de seus efeitos e da falta de estruturas para que elas realmente aconteçam, mas é bem verdade que eles, mesmo com limitações e problemas, vêm contribuindo para que a Educação Inclusiva seja muito mais do que discurso ideológico, fenômeno de retórica ou modismo importado. [...] Foi possível, por meio desta pesquisa, verificar que outros sujeitos e entidades estão imbuídos nesse processo como Instituições de Ensino Superior, por meio de seus pesquisadores suas produções; professores/pesquisadores/escritores que vêm dando ampla visibilidade sobre esta modalidade de ensino através de suas obras (ALVES, 2018, p. 103-104).

Nesse contexto, procuramos trabalhar com nossos alunos com deficiência, seja ela qual for, ao considerarmos processos em (des)construção de saberes em (trans)formações. Compreendemos pertinentes, pois, mudanças, sobretudo em nossos discursos em práxis do dia a dia, em que procuramos não dissociar

[...] termos, inclusão e exclusão, pois compreendemos que vivemos num tempo onde a inclusão se sustenta como um imperativo contemporâneo inquestionável e que por isso é por dentro dela que os processos de exclusão são produzidos. [...] todas essas políticas não garantem o inverso da exclusão, ou seja, não garantem uma inclusão permanente desses sujeitos, como se tivéssemos cruzado a linha de chegada do verdadeiro projeto inclusivo. Por esse motivo usamos a expressão in/exclusão, para definir essa condição nômade e movediça que constitui a todos nós, nesses tempos incertos (LOCKMANN, 2019, p. 1).

\section{Como nos movimentamos...}

No início do nosso pesquisar, observamos e analisamos a maneira como os alunos diagnosticados com deficiência intelectual interagiam com professores e com colegas de sala. Percebemos um sentimento de in/exclusão desses alunos em relação às atividades propostas, a falta de atividades adaptadas que contemplasse o conteúdo que estava sendo trabalhado, de maneira que o aluno, diante das suas possibilidades, pudesse ser inserido naquele momento no contexto da sala de aula. Observamos que, para um aluno com deficiência intelectual, que ainda não sabe ler, não é coerente lhe apresentar o livro didático com textos enormes que não lhe dizem nada, ou seja, não fazem sentido algum; é preciso uma adaptação, com frases curtas e imagens em que o aluno terá a possibilidade de assimilar o que o professor explica.

A partir de uma conversa com a professora de Ciências e com a professora do AEE, percebemos a importância de adaptar materiais que pudessem ajudar esses alunos na compreensão 
dos saberes de Ciências. Com o olhar sobre essa disciplina, encontramos várias possibilidades de reorganização dos saberes para adaptação aos estudantes com deficiência intelectual. Assim, foi possível avaliarmos quais eram as dificuldades e também o potencial de cada aluno. Além disso, observamos quais as dificuldades que a professora encontrava no planejamento das aulas. Desde então, começamos a confeccionar e a organizar alguns materiais pedagógicos, como jogos e atividades adaptadas aos conteúdos de Ciências que foram trabalhados nas aulas, durante o estágio em Ciências, no ensino fundamental, da Escola Municipal Dr. Getúlio Vargas, onde uma das autoras do artigo, conforme já mencionamos, trabalhava como monitora. Ao aplicarmos as atividades adaptadas, ratificamos o que já pensávamos: que a inclusão é um processo desafiador, pois requer tempo do professor para a preparação do material, para criar, além de necessitar do auxílio de um profissional de apoio que, muitas vezes, as escolas não oferecem aos alunos. Chegamos a uma compreensão de que tudo transcorre somente a partir da responsabilidade do professor que deve criar condições para que o aluno se sinta integrado, legitimado e, ao mesmo tempo, o docente, deve estar atento em relação ao restante da turma. Por outro lado, percebemos a mudança no aluno, a participação e a interação com os demais alunos e, ainda, observamos e sentimos a satisfação e a alegria do aluno ao se sentir valorizado e capaz de realizar as atividades proporcionadas.

\section{Atividades lúdicas...}

Ensinar uma criança com deficiência intelectual que apresenta especificidades no seu desenvolvimento cognitivo e motor é um processo que exige muito estímulo e o uso de ferramentas que possam facilitar o processo de aprendizagem. Sendo assim, enfatizamos, que os jogos e as brincadeiras, por mais simples que sejam, ajudam no desenvolvimento cognitivo, afetivo e social da criança por possibilitar condições de interação. A primeira atividade que desenvolvemos, no sexto ano, foi sobre o ciclo da água e envolveu práticas lúdicas de colagem de pintura. Solicitamos que os alunos recortassem e colassem, no respectivo lugar, as palavras: vapor de água, calor, chuva, mar, rio, lagoa (Figura 1). Proporcionamos, com essa prática, uma relação entre linguagem verbal e não verbal.

Figura 1: Atividade 1 - Ciclo da Água

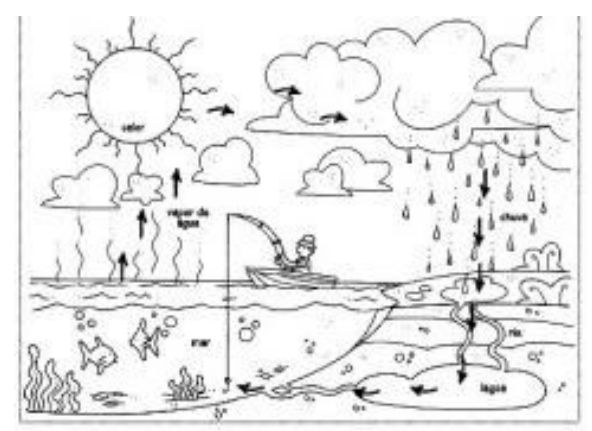

Fonte: Elaborado pelas autoras. 
Nessa atividade, o aluno assistiu à aula sobre o ciclo da água e, após, com a ajuda do monitor, realizou a atividade que possibilitou ao estudante visualizar e interagir com o ciclo da água, ao permitir que ele escolhesse o lugar da colagem, conversasse com o monitor e, assim, construísse sua compressão. Na segunda atividade (Figura 2), desenvolvida no sétimo ano, o jogo da memória (animais vertebrados e invertebrados), que buscamos na internet, o aluno recortou e colou em folha $60 \mathrm{k}$, construindo o jogo da memória. Logo em seguida, jogou com um colega de sala e identificou, através das imagens, os animais vertebrados e invertebrados. Com essa atividade, permitimos que houvesse condições para que o estudante tivesse uma socialização com os demais colegas e se sentisse incluído, compreendesse a importância das regras, tanto no jogo como na relação com o outro, além de estabelecer relações associativas por semelhança, isto é, aproximar o que se parece pelo exercício da memória.

Figura 2: Atividade 2 - Jogo da Memória

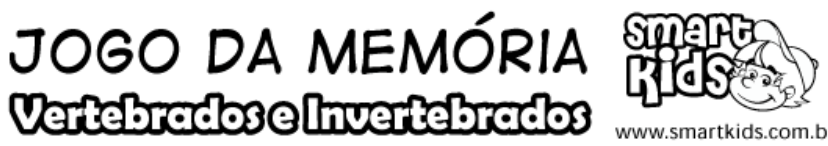

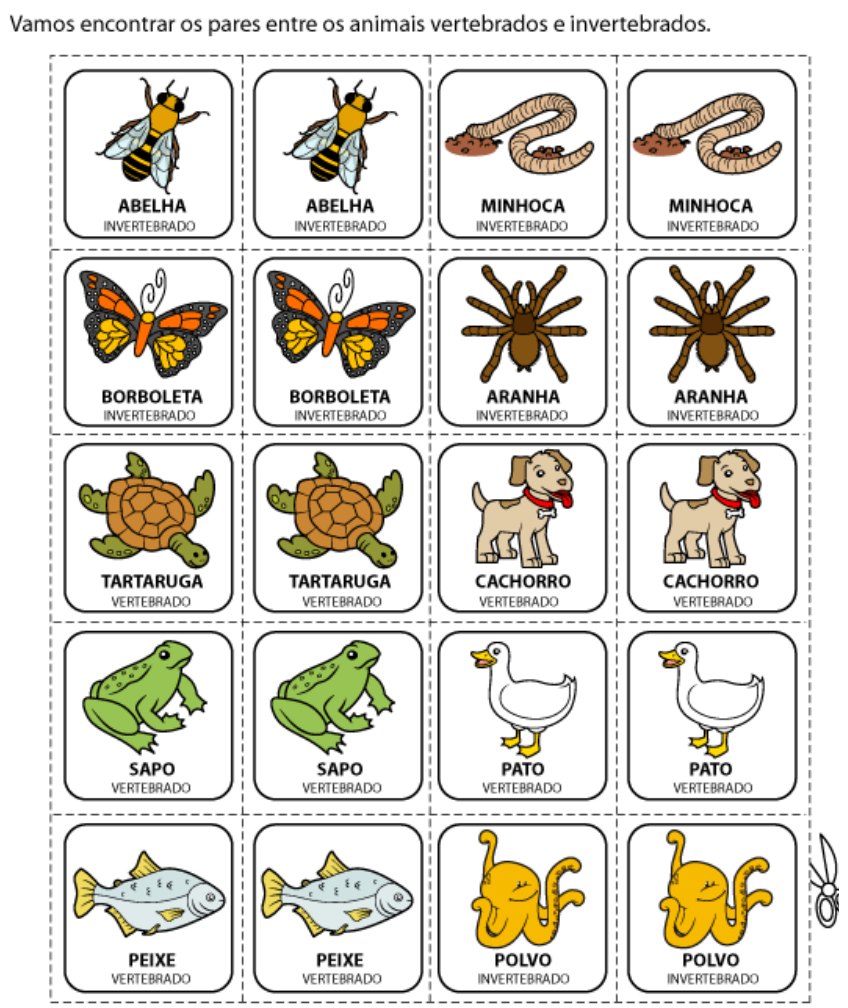

Fonte: Disponível em: http://www.smartkids.com.br/jogo/jogo-da-memoria-vertebrados-e-invertebrados. Acesso em: 12 ago. 2017.

Na construção da maquete sobre animais domésticos e selvagens, terceira atividade no sétimo ano, o aluno recebeu alguns animais, os quais deveria pintar, recortar e, então, montar um cenário com animais selvagens e com animais domésticos. Com essa prática, o aluno identificou alguns animais e soube dizer onde viviam. Além de desenvolver habilidades como pintar e recortar, o aluno demonstrou sentir-se capaz e satisfeito com o cenário que construiu. Na atividade quatro (Figuras 3 e 4), proporcionamos a montagem do boneco articulado. 
Figura 3: Montagem do boneco articulado

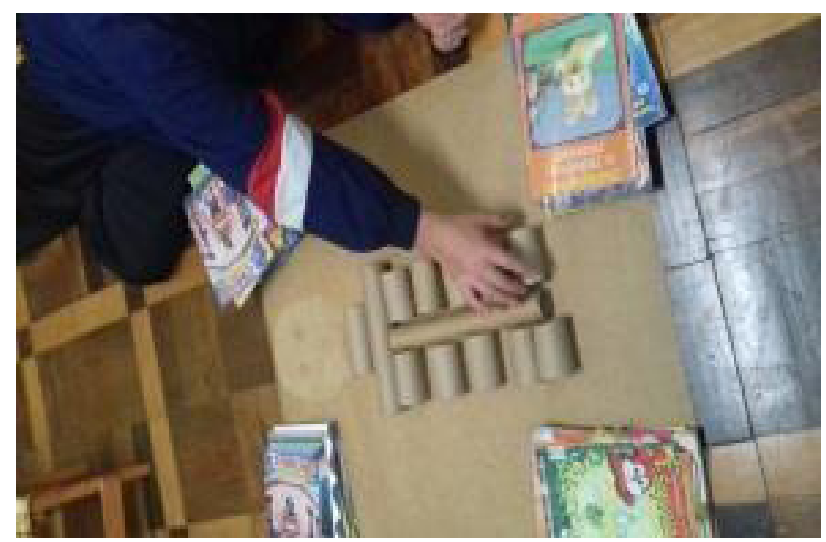

Fonte: Elaborado pelas autoras.

Figura 4: Boneco articulado montado

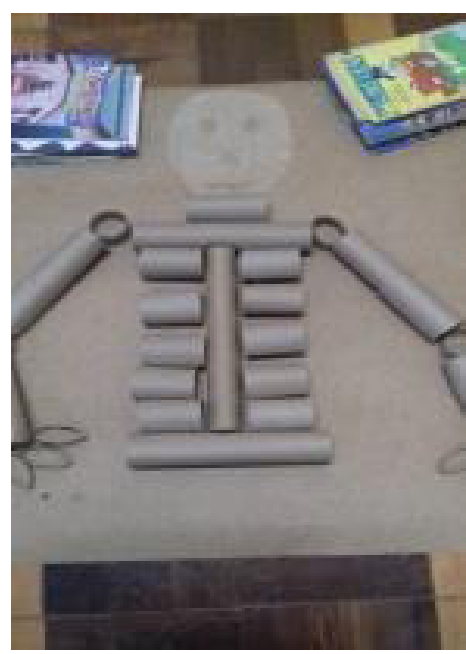

Fonte: Elaborado pelas autoras.

Essa atividade foi realizada com um aluno do oitavo ano. No momento em que a professora iniciava o conteúdo do corpo humano na turma, foi mostrada para o aluno uma imagem de um boneco articulado que havia sido criado com hastes flexíveis e, a partir dessa imagem, o aluno construiu, com ajuda da monitora, o boneco e usou como matéria-prima rolinhos de papel higiênico, para melhor manuseio. Além disso, trabalhamos a importância da reciclagem de materiais, uma vez que o próprio aluno coletou em casa os rolinhos que foram usados para a confecção do boneco. Percebemos que o aluno se sentiu bastante satisfeito e entusiasmado, pois apresentamos o boneco por ele construído para explicar aos demais colegas sobre a composição do corpo humano. A partir da atividade cinco (Figura 5), no oitavo ano, possibilitamos ao aluno a modelagem das células eucariontes e procariontes com massa de modelar. Dessa maneira, ele construiu a representação celular. 
Figura 5: Modelagem das células eucariontes e procariontes

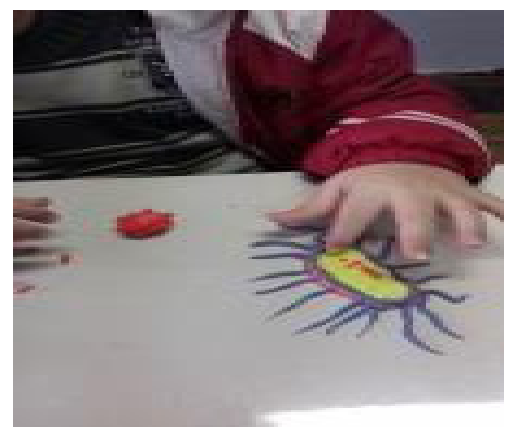

Fonte: Elaborado pelas autoras.

Nessa atividade foi possível trabalharmos a coordenação motora do aluno e a sua percepção diante da imagem que lhe apresentamos. Pudemos perceber que ele trabalhou com satisfação e dedicou-se com afinco à realização dessa prática na tentativa de fazer o mais perfeito possível, o que demonstrou interesse e prazer por parte do aluno. Já com a atividade seis (Figura 6), objetivamos trabalhar sobre a utilidade da água.

\section{Figura 6: Para que serve a água?}

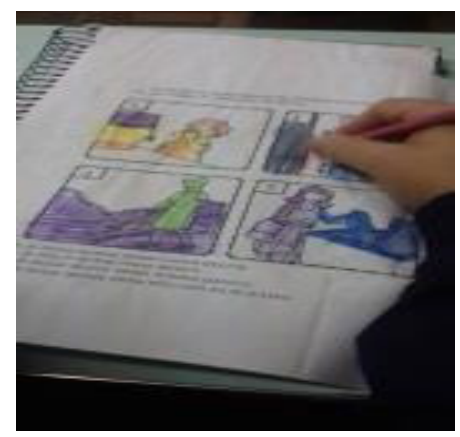

Fonte: Elaborado pelas autoras.

Com essa atividade que desenvolvemos no sexto ano, o aluno coloriu as imagens e numerou, com a ajuda de um colega, as atividades do dia a dia em que utiliza a água. $\mathrm{O}$ trabalho em conjunto com o colega foi interessante para a socialização do aluno que se sentiu feliz com a ajuda, com o momento de interação. Ainda com essa atividade, trabalhamos a importância de economizar água para preservação dos recursos naturais do planeta. E, na atividade sete (Figura 7), no sexto ano, estudamos sobre o funcionamento da estação de tratamento de água.

Figura 7: Estação de tratamento de água

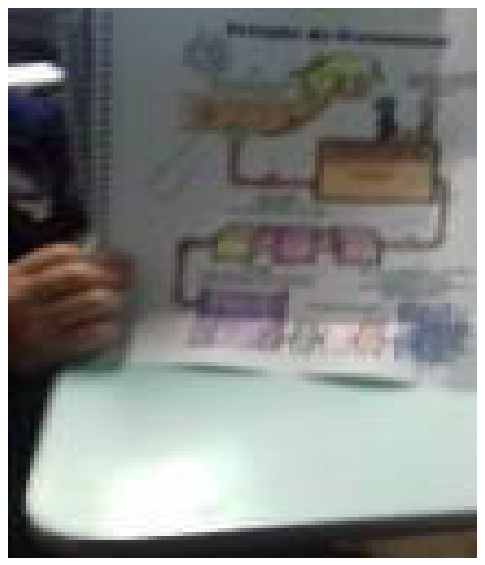

Fonte: Elaborado pelas autoras 
Para isso, apresentamos para o aluno uma imagem impressa em folha A4, representativa de como funciona o tratamento da água, de forma bastante simples, clara e objetiva. O aluno observou a imagem impressa e pintou da maneira que achou conveniente, da maneira como sentiu e como compreendeu. Com essa atividade, procuramos desenvolver no aluno a coordenação motora. Gostaríamos de salientar que o aluno demonstrou ser capaz de realizar a tarefa sem ajuda de colegas ou da monitora. Isso nos parece relevante para a construção da autonomia e da confiança, tão necessários no movimento do ensinar e do aprender.

Para desenvolvermos as atividades propostas, percebemos que muitos desafios precisaram ser superados; destacamos, então, o primeiro, que foi conquistar os alunos e fazer com que eles se sentissem felizes e pertencentes ao espaço de convivência da sala de aula para, então, se tornarem protagonistas da sua própria aprendizagem. Diante desse contexto, destacamos a dedicação e a persistência de todos os envolvidos no processo na realização das tarefas, ao incentivar, auxiliar e motivar a realização das atividades. Observamos que o conversar entre a professora de Ciências e a professora da sala de AEE, com a monitora, contribuiu para o desenvolvimento dos alunos que se mostraram mais sociáveis ao interagir e ao reagir aos diferentes desafios propostos. Percebemos que a capacidade de resolver problemas, bem como a reação dos alunos, na condição de sujeitos autopoiético-discursivos que se ressignificam, expressaram significativa melhora nas habilidades de colagem e nos jogos.

Por experiência, podemos dizer que a satisfação de contribuir para o crescimento e o desenvolvimento dos alunos com deficiência intelectual supera algumas das frustrações com as quais nos deparamos quando não somos compreendidos pelos alunos, quando eles não realizam as atividades propostas ou, até mesmo, quando, devido à sua deficiência, se tornam agressivos, podendo não considerar o material que preparamos. Essas são situações que podem ocorrer, mas, ao conseguirmos que o aluno com deficiência intelectual melhorasse sua socialização, seu desenvolvimento, sua consciência em relação às suas potencialidades e aos seus limites, nos sentimos satisfeitas pelo apoio que, com amor, foi movimentado pelos nossos desejos de acompanhar suas aprendizagens e construções em processos que não têm tempo nem pressa, têm apenas sentidos e sentires; interessante deixar o fluir dos sentidos em emergência. Somente nessas condições legitimamos e somos legitimados como nos convida a Biologia do Conhecer e a Biologia do Amar.

Compreendemos que a autonomia e a interação com o outro são o fio condutor do ensinar e do aprender. Essa autonomia compreende um sujeito autônomo em rede com outras tantas autonomias que vão se constituindo e se ressignificando, justamente, no processo que nos conjuga ao outro em suas subjetividades. Primamos por um ensinar e por um aprender que façam sentido a todos os envolvidos nesse processo de extrema complexidade. A aula não pode ser pensada como um ritual ou apenas como espaço de saberes científicos desvinculados da realidade social, mas precisa atender à multiplicidade de fatores e de expectativas do aluno e do professor. Hoje em dia, uma sociedade mutante, difusa, altamente tecnológica, de grande exigência profissional, traz para a sala de aula outras e diferentes formas de repensar que não dispensam o conversar em sentires com o outro. Sabemos que todo ato humano ocorre na linguagem em ação que produz o mundo que se cria com os outros, no ato de convivência que dá origem ao humano. Por isso, toda ação humana tem sentido ético. Essa ligação do humano ao humano é, em última instância, o fundamento de toda ética como reflexão sobre a legitimidade da presença do outro (MATURANA; VARELA, 2011).

\section{Considerações em movimentos...}

Para refletirmos sobre a relação entre o fazer e o ser, especificamente, no que se refere à prática docente, apresentamos neste trabalho condições de possibilidade de interação entre sujeitos autopoiético-discursivos em transformações recursivas. Diante do que apresentamos, podemos 
afirmar que a escola, o professor e a comunidade escolar, a família e os colegas podem possibilitar ao aluno, sujeito autopoiético-discursivo em processos de reinvenção com deficiência intelectual, um ambiente acolhedor que possa favorecer o processo do ensinar e do aprender. Isso implica mudança do contexto escolar, da metodologia do professor da classe regular, que deve agregar esforços com o professor da sala de recursos a fim de possibilitar condições para a construção dos saberes. A linguagem em gestos discursivos encanta pelo entrelace emoção e razão, pelo conversar com o lúdico. Ao começarmos a confecção do material, percebemos, fortemente, que o processo de inclusão é um desafio para os educadores e que a preparação do material requer tempo por parte do professor que, muitas vezes, precisa desenvolver, para uma mesma turma, diferentes planos de aula. Compreendermos que o planejamento seja flexível nos parece, sobremaneira, pertinente no processo complexo do ensinar e do aprender para alunos com deficiência intelectual. Respeitarmos o tempo e o ritmo de cada aluno é essencial nos processos do ensinar e do aprender. Precisamos investir em tempo de estudo, em interesse e em preparo para estar com, ou seja, para trabalhar com esses alunos. À escola, então, é urgente que passe a assumir seu papel e destinar a atenção que esses alunos merecem e de que precisam ao despertar, com amor, sentires em afetos. Salientamos que a aceitação da comunidade escolar, dos professores e dos alunos pelo diferente é necessária para uma convivência que inclua e que responsabilize a todos pelos direitos, pelas escolhas e pelos deveres. Não menos urgente é a compreensão de que o atuar cooperativo entre professores de diferentes áreas, a incluir o professor responsável pelo AEE, faz total diferença no processo; é a premência da lógica e da emoção da cooperação em todas as instâncias da escola, quiçá da sociedade.

Consideramos que o aluno com deficiência intelectual necessita de um acompanhamento diferenciado, com auxílio de monitor e com utilização de material adaptado, que oportunize ações específicas que o levem a desenvolver habilidades ainda não potencializadas. Assim, acreditamos que quando o professor respeita as diferenças e consegue adaptar sua rotina, proporciona um ensino personalizado que faz da escola, realmente, uma instituição que promove a inclusão. A conversa, entre o professor de Ciências, a monitora e a professora da sala de recursos, demonstra que são pequenas ações no grupo de professores que fazem a diferença no contexto da escola. E isso nos motiva a criar possibilidades para a construção de saberes e para a participação efetiva desses alunos com deficiência intelectual, os quais estão à margem do sistema. Fazer o que está ao nosso alcance tem muito mais valia do que delegarmos desafios sem o comprometimento necessário de quem aprende e de quem ensina. Muitos jogos e atividades podem ser confeccionados dentro da própria instituição escolar, com materiais simples como um rolo de papel higiênico na confecção do corpo humano, por exemplo, bem como outras práticas simples que fazem a diferença ao educando.

No momento em que a escola, a comunidade escolar e os professores assumirmos uma postura inclusiva não existirão diferenças entre alunos com diagnóstico de deficiência e alunos regulares e todos estaremos em um único processo que será construído no sentido de respeitar as diferenças, de superar desafios e de tornar a inclusão uma realidade possível. Podemos dizer ainda que o maior ganho do aluno com deficiência intelectual, a partir do momento em que começou a realizar as tarefas propostas, foi o entusiasmo e o prazer com que participou e com que interagiu com os colegas, discentes regulares, pois possibilitamos condições para a sua sociabilidade e para a realização de diferentes atividades lúdicas. Corroboramos que o lúdico é um recurso, em potencial, em suas emergências pela interação.

Procuramos pensar, neste artigo, sobre a utilização dos jogos na construção do processo do ensinar e do aprender diferentes saberes na disciplina de Ciências para alunos com deficiência intelectual e, para tal, apresentamos algumas singelas atividades, as quais realizamos e, assim, ratificamos que essas práticas interativas possibilitam inclusão e participação coletiva que se efetivam pela interação e pela aceitação do outro. Diante disso, acreditamos que a ação cooperativa entre professores e profissionais capacitados seja uma alternativa viável para o trabalho inclusivo nas escolas do século XXI. Afinal, resgatamos que só estamos a falar em inclusão, pois somos uma 
sociedade que exclui. Aqui, o convite às transformações que exigem de nós amor que legitima em nossos fazeres docentes. Interagir com emoções e com razões engendradas nos autoriza a legitimar o outro como legítimo outro.

Sigamos a lançar olhares em vivências, na sala de aula, aos desafios com nossos alunos com deficiência intelectual que nos convidam a seguir pela objetividade entre parênteses, a ressignificar o ensinar e o aprender Ciências, com atividades lúdicas pelas quais legitimamos e somos legitimados...

\section{Referências}

ALVES, Augusto Marques. Avaliação da aprendizagem da pessoa com deficiência intelectual: análise de teses e dissertações brasileiras. 117p. 2018. Dissertação (Mestrado) - Programa de Pós-Graduação em Educação Especial, do Centro de Educação e Ciências Humanas, Universidade Federal de São Carlos, UFSCar, 2018.

AMPUDIA, Ricardo. O que é Deficiência Intelectual? Disponível em: http://novaescola.org.br/conteudo/271/o-que-e-deficiencia-intelectual. Acesso em: 28 out. 2017.

BRASIL. Decreto No 6.949, de 25 de agosto de 2009. Promulga a Convenção Internacional sobre os Direitos das Pessoas com Deficiência e seu Protocolo Facultativo, assinados em Nova York, em 30 de março de 2007. Diário Oficial da União: seção 1, Brasília, DF, p. 3, 26 ago. 2009. Disponível em: http://www.planalto.gov.br/ccivil_03/_ato2007-2010/2009/ decreto/d6949.htm. Acesso em: 25 set. 2017.

COSTA, Renata. Planejamento: momento de repensar a escola. In: Revista nova escola. jan. 2010.

DELEUZE, Guilles; GUATTARI, Félix. Mil Platôs: capitalismo e esquizofrenia 2, vol. 4. Tradução de Suely Rolnik. 2. ed. São Paulo: Editora 34, 2017.

KASTUP, Virgínia; PASSOS, Eduardo; TEDESCO, Silvia. In: KASTRUP, Virgínia; PASSOS, Eduardo; TEDESCO, Sílvia. (org.). Políticas da cognição. Porto Alegre: Sulina, 2008. p. 9-17.

LOCKMANN, Kamila. A BNCC e os processos de in/exclusão: novas reconfigurações? Palestra apresentada no Colóquio Internacional de Educação Especial e Inclusão Escolar, Florianópolis: Universidade Federal de Santa Catarina - UFSC, junho 2019.

MAFRA, Sonia Regina Corrêa; KEMPA, Sydnei Roberto. O lúdico na prática educacional de alunos com deficiência intelectual, 2009. Disponível em: http://www.diaadiaeducacao.pr.gov.br/portals/pde/arquivos/2444-8.pdf. Acesso em: 25 set. 2017.

MANTOAN, Maria Teresa Eglér. Ensinando a turma toda: as diferenças na escola. In: O desafio das diferenças nas escolas. Rio de Janeiro: Vozes, 2008. p. 59-68.

MANTOAN, Maria Teresa Eglér. Inclusão escolar: O que é? Por quê? Como fazer? São Paulo: Moderna, 2003.

MANTOAN, Maria Teresa Eglér. O direito de ser, sendo diferente, na escola. In: RODRIGUES, David. (org.). Inclusão e educação: doze olhares sobre a educação inclusiva. São Paulo: Summus, 2006. p. 183-210.

MATURANA, Humberto; VARELA, Francisco. A árvore do conhecimento: as bases biológicas da compreensão humana. Tradução Humberto Mariotti; Lia Diskin. 9. ed. São Paulo: Palas Athena, 2011.

MATURANA, Humberto. Emoções e Linguagem na educação e na política. Tradução José Fernando Campos Fontes. Belo Horizonte: UFMG, 2009.

MATURANA, Humberto. Cognição, ciência e vida cotidiana. 2. ed. Belo Horizonte: UFMG, 2014a.

MATURANA, Humberto. A ontologia da realidade. (org.). MAGRO, Cristina; GRACIANO, Miriam; VAZ, Nelson. 2. ed. Belo Horizonte: Editora UFMG, 2014b.

MATURANA, Humberto; YÁÑES, Ximena. El Arbol del Viver. Escuela matrística. MVP Editores, 2015.

MENDONÇA, Regina Celia Avilha. A aprendizagem do aluno com deficiência intelectual e a prática pedagógica em questão. 68p. Monografia - Especialização em desenvolvimento Humano, Educação e Inclusão - Universidade Aberta do Brasil, Universidade de Brasília, Espírito Santo, 2011. 
MRECH, Leny Magalhães. O que é educação inclusiva. Faculdade de Educação da Universidade de São Paulo. São Paulo: Edusp, 2001.

OLIVEIRA, Anna Augusta Sampaio de. Adequações curriculares na área da deficiência intelectual: algumas reflexões. In: OLIVEIRA, Anna Augusta Sampaio de; GIROTO, Claudia Regina Moscas. Inclusão Escolar: as contribuições da Educação Especial. São Paulo: Editora Fundepe: Cultura Acadêmica, 2008. p. 129-154.

ORGANIZAÇÃO DAS NAÇÕES UNIDAS (ONU). Declaração de Salamanca: sobre princípios políticas e práticas na área das necessidades educativas especiais. Salamanca: ONU, 1994. Disponível em: http://portal.mec.gov.br/seesp/ arquivos/pdf/salamanca.pdf. Acesso em: 19 nov. 2017.

PASSOS, Eduardo; ESCÓSSIA, Liliana da; KASTRUP, Virgínia. (org.). Pistas do método da cartografia: Pesquisa-intervenção e produção de subjetividade. v. 1. Porto Alegre: Sulina, 2014.

RASILCHIK, Myriam. Prática de ensino de biologia. 4. ed. São Paulo: Edusp, 2008.

SANTOS, Santa Marli Pires dos. (org.). A ludicidade como uma ciência. Petrópolis: Vozes, 2001.

TEDESCO, Silvia. Estilismo de si: ato de fala e de criação In: KASTRUP, Virgínia; PASSOS, Eduardo; TEDESCO, Silvia. (org.). Políticas da cognição. Porto Alegre: Sulina, 2008.

VERDE, Adriana Lima. Atendimento Educacional Especializado: do aluno com deficiência intelectual. São Paulo: Moderna, 2010.

Data de submissão: 13/05/2021

Data de aceite: $25 / 06 / 2021$ 